\title{
Conflito entre teoria da vontade real e a teoria da declaração na Escada Ponteana
}

\author{
Conflict between real will theory and declaration theory \\ on the Ponteana Ladder
}

Melissa Pinheiro Almeida

Universidade de São Paulo/SP

RESUMO Esta pesquisa objetivou investigar as teorias doutrinárias existentes e suscitadas diante de um conflito envolvendo o elemento vontade dentro do negócio jurídico, questionando-se qual delas prevalece no atual sistema brasileiro. Para tal, buscou-se um comparativo entre as duas correntes mais relevantes, seus fundamentos e aplicabilidades, fazendo-se uso do método dedutivo para restringir a matéria, partindo de uma análise de conceitos, das proposições da doutrina, bem como, da legislação para, finalmente, se reconhecer o posicionamento vigente. Considerando-se que a questão muito divergiu ao longo do tempo, foi possível verificar que, hoje, a literatura civilista concorda que o negócio jurídico se sustenta em elementos didaticamente descritos pela Teoria da Escada Ponteana como planos, quais sejam: existência, validade e eficácia. A interdependência desses planos é uma premissa. Contudo, em caso de manifestação de vontade defeituosa na formação do negócio, há duas teorias mais populares passíveis de adoção para resolução: a Teoria da Vontade Real e a Teoria da Declaração, pelas quais foi possível concluir que, em que pese a celeuma histórica entre as duas, atualmente o ordenamento jurídico brasileiro tende a favorecer a primeira, não obstante o exame das particularidades do caso concreto, isto é, admitindo-se a mitigação do posicionamento.

Palavras-chave: Negócio Jurídico. Escada Ponteana. Teoria da Vontade Real. Teoria da Declaração.

ABSTRACr This research aimed to investigate the existing doctrinal theories raised face of a conflict involving the element of will within the legal business, questioning which of them prevails in the current brazilian system. To this end, a comparison was sought between the two most relevant currents, their foundations and applicability, making use of the deductive method to restrict the issue, starting from an analysis of concepts, the propositions of doctrine, as well the legislations, to finally recognize the current position. Considering that the matter diverged a lot over time, it was possible to verify that, today, the civilist literature 
agrees that the legal business is based on elements didactically described by the Ponteana Ladder Theory as plans, namely: existence, validity and effectiveness. The interdependence of these plans is a premise. However, in case of manifestation of defective will in the formation of the business, there are two more popular theories that can be adopted for resolution: the Theory of the Real Will and the Theory of Declaration, so it was possible to conclude that, despite the historical stir between both, currently the brazilian legal system tends to favor the first, although considering the examination of the particularities of the specific case, that is, admitting the mitigation of its position.

Keywords: Legal business. Ponteana Ladder. Real Will Theory. Declaration Theory.

\section{INTRODUÇão}

O ser humano, como ser social, busca satisfazer parte de seus anseios por intermédio de vínculos com outros, dos quais depende para suprir suas necessidades, que se formam a partir de convenções. Estas, por sua vez, se concretizam por meio do que se conhece por negócio jurídico.

Antes de qualquer observação acerca do negócio jurídico, convém diferenciá-lo de outros termos semelhantes e que estão próximos no estudo civilista, porém se distinguem no significado, quais sejam: fato jurídico e ato jurídico. Augusto Passamani Bufulin (2012) ensina que fato jurídico é todo acontecimento cujo direito empresta importância, sendo ele um termo genérico do qual derivam duas espécies: i) fatos jurídicos independentes da vontade humana, também chamados de fato jurídico em sentido estrito, que podem ser naturais (raio que destrói uma propriedade) ou humanos (nascimento e morte); e ii) fatos jurídicos dependentes da vontade humana, também chamados de ato jurídico.

Os atos jurídicos podem ser: i) ilícitos, quando não estão em concordância com a ordem jurídica; ou ii) lícitos, quando de acordo. Estes têm ainda como espécies A) atos jurídicos em sentido estrito; e B) negócio jurídico (BUFULIN, 2012). A atenção neste trabalho se volta para o último citado.

Superada a chance de qualquer engano terminológico, a questão aqui suscitada busca ir além do momento de formação do negócio jurídico. Uma vez negociado, avalia-se não apenas o cumprimento do pacto, mas a hipótese de avença decorrente de questionamento da genuinidade volitiva, isto é, no que ocorre mediante qualquer alegação de vício de vontade.

Surgem, portanto, duas teorias dispostas a elucidar a questão: a Teoria da Vontade Real e a Teoria da Declaração. Assim, o que ora se pretende examinar são quais as razões norteadoras das duas teorias a fim de compará-las e assinalar qual é compreendida na ordem brasileira vigente. Cumpre informar que esta pesquisa não ambiciona esgotar o tema nem inovar na comunidade científica, mas sim oferecer os parâmetros mínimos tangentes das teses postas em xeque.

Para tanto, a pesquisa contou com fontes secundárias, por meio de revisão bibliográfica doutrinária e da legislação vigente no ordenamento jurídico, servindo-se do método dedutivo para restringir as teorias conflitantes como objeto de estudo a partir de uma ótica mais ampla. 
Assim, o trabalho objetivou, primeiramente, explorar conceitos elementares e seus paradigmas, partindo do negócio jurídico e suas particularidades em relação às outras figuras encontradas no seio das obrigações. A seguir, o trabalho detalhou a Teoria da Escada Ponteana e sua relevância para a compreensão da estrutura do negócio de seus três planos. Sucedendo, verificou-se o elemento vontade como componente capital e todo o cuidado interpretativo que lhe é reservado. E finalmente, após contextualização, voltou-se a atenção para o conflito entre as duas teorias majoritárias e as condições que as regem.

\section{O NegóCio JURÍDico}

Ao indivíduo capaz de criar relações por meio de sua vontade, desde que não destoe da lei, é concedida uma prerrogativa que se expressa por meio do negócio jurídico (RODRIGUES, 2002). Nenhum instituto manifesta a liberdade humana com tanta clareza quanto o negócio jurídico, oferecendo a autonomia da vontade não apenas à regulamentação dos interesses privados, mas efeitos práticos (VELOSO, 1995).

O pandectismo alemão do século XIX propulsionou a criação do Rechtsgeschäft, o negócio jurídico, como figura autônoma. Uma vez desenvolvida, tal doutrina se expandiu por toda a Europa, apesar de não triunfar na França, se tornando hoje uma figura mundialmente reputada (VELOSO, 1995).

De modo semelhante, Gonçalves (2016a) escreve que o primeiro diploma legal a atribuir um regime específico ao negócio jurídico (Rechtsgeschäft) foi o Código Civil alemão (BGB). Da Alemanha, a dogmática partiu para a Itália, Espanha e Portugal. No entanto, o Brasil acompanhou a doutrina unitária francesa que não distinguia o negócio jurídico do ato jurídico.

De modo diferente, porém, do Código Civil brasileiro de 1916, o código posterior promulgado em 2002 adotou a teoria dualista, expressando alterações e evidente separação entre a figura do negócio e do ato jurídico. Seguindo orientação do Código Civil português de 1966, abriu um título específico para o ato jurídico, cujo único artigo requer que se aplique, no que couber, os dispositivos legais do negócio jurídico. Assim, constatou-se o desaparecimento da expressão genérica ato jurídico, dando espaço para o negócio jurídico se desenvolver como referência específica (GONÇALVES, 2016a).

Deriva-se do direito romano a classificação tradicional dos elementos do negócio jurídico, cuja divisão apresenta: elementos essenciais (essentialia negotii), elementos naturais (naturalia negotii) e elementos acidentais (accidentalia negotii). Os elementos essenciais se referem àquilo que é indispensável na estrutura do negócio, sem a qual não seria possível o mesmo existir. Os elementos naturais se referem aos efeitos que decorrem da natureza do negócio, sendo, portanto, consequências que não carecem de menção expressa (GONÇALVES, 2011).

E por fim, os elementos acidentais se referem aos acessórios, isto é, estipulações que as partes facultam acrescentar ao negócio para trazer um efeito diverso das consequências naturais, significando que não são elementos necessários à existência. Porém, uma vez convencionados, passam a integrar o negócio. O direito brasileiro apresenta três elementos acidentais: a condição, o termo e o encargo/modo (GONÇALVES, 2011). 
Segundo Marcos Bernardes de Mello (1993), o negócio jurídico se revela por meio da manifestação de vontade humana em suas interações sociais. O propósito dessa manifestação é um resultado jurídico previsto no ordenamento e que não o contradiga.

No negócio jurídico a manifestação de vontade possui fim negocial que, de forma genérica, significa criar, adquirir, transferir, modificar e extinguir direitos, por meio de condutas regidas a partir da composição de interesses. O contrato é a espécie de negócio jurídico bilateral mais expressiva, nascendo do acordo de vontades que mescla manifestações individuais, sendo estas, quando conscientemente produzidas, o primeiro e mais importante requisito para existência do negócio no mundo das relações jurídicas (GONÇALVES, 2016a).

Mas para se compreender, verdadeiramente, o que é negócio jurídico é imperativo olhar desde logo para sua composição basilar, antes de se pretender atestar sua finalidade, espécies e posições controversas acerca de suas consequências. É essa composição que ora se passa a averiguar.

\subsection{A Escada Ponteana}

Ao estudar o negócio jurídico, é elementar que sua estrutura seja analisada sob a Teoria da Escada Ponteana, que traduz a ideia de divisão em planos (ou degraus, como sugere o nome). Tal teoria recebe esse nome porque foi trazida para o Brasil pelo doutrinador Pontes de Miranda, e aponta três planos como alicerce do negócio jurídico: o da existência, validade e eficácia.

Humberto Theodoro Jr. (2001) escreve que é imprescindível a passagem por esses três planos do mundo jurídico para que a declaração de vontade atinja o efeito pretendido pelo agente. A não integração dos elementos do plano da existência, validade e eficácia, leva à frustração do resultado de interesse.

Ensina o precursor da teoria, Pontes de Miranda (1974, p. 15):

\footnotetext{
Existir, valer e ser eficaz são conceitos tão inconfundíveis que o fato jurídico pode ser, valer e não ser eficaz, ou ser, não valer e ser eficaz. As próprias normas jurídicas podem ser, valer e não ter eficácia. O que não se pode dar é valer e ser eficaz, ou valer, ou ser eficaz, sem ser; porque não há validade, ou eficácia do que não é.

"Para que algo valha é preciso que exista. Não tem sentido falar-se de validade ou invalidade a respeito do que não existe.

A questão da existência é uma questão prévia. Somente depois de se afirmar que existe é possível pensar em validade [...]"

(PONTES DE MIRANDA, 1954, p. 7).
}

De modo geral, os pressupostos de existência do negócio jurídico são chamados de elementos constitutivos, visto que são basilares para a formação, isto é, não existe negócio sem agente, objeto e forma. Já no plano da validade, os elementos constitutivos são adjetivados. Isto é, nesse plano não basta que haja agente, é necessário que este seja capaz. De modo semelhante ocorre com o objeto, que deve ser lícito, possível, determinado ou determinável. E quanto à forma, deve ser a prescrita ou não defesa em lei (TARTUCE, 2012). 
Para adquirir, modificar ou extinguir direitos, isto é produzir efeitos na seara jurídica, o negócio deve atender aos requisitos de validade já listados. Se atende, ele é válido, se não, inválido, tornando-se nulo ou anulável, sem alcançar a finalidade pretendida pelo agente. Assim, verifica-se que os requisitos de validade se dividem em subjetivos, objetivos e formais (GONÇALVES, 2016a).

É a redação do artigo 104 do Código Civil brasileiro de 2002:

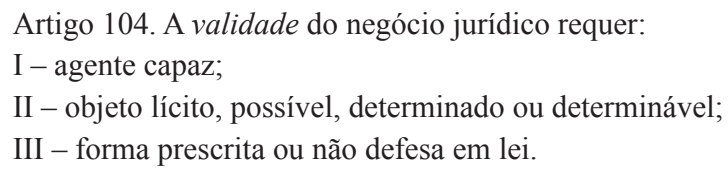

Quanto ao plano da eficácia, ele se apresenta ao mundo jurídico como sendo o momento em que os fatos finalmente produzem seus efeitos e repercutem nas relações jurídicas, nos limites do que foi projetado pela vontade negocial (MELLO, 1993). Assim, reafirma Theodoro Jr. (2001) que nesse plano se cogita tão-somente a condição do negócio em produzir efeitos. Não se discute mais existência nem validade. Apenas a possibilidade (ou não) do resultado jurídico, movendo o questionamento se este é eficaz ou ineficaz.

É possível que um negócio jurídico esteja subordinado a um acontecimento futuro, significando que ele pode existir, ser válido, porém ineficaz. O negócio apenas produzirá efeitos com a chegada do acontecimento previsto, tornando-se exigível (GAGLIANO, 2006).

Dessa forma, observado os pressupostos de cada plano, cumpre dizer que a perfeição do negócio jurídico está condicionada à ausência de qualquer vício invalidante, como vício de consentimento e incapacidade do agente, conforme prevê o Código Civil brasileiro vigente (THEODORO JR., 2001).

É a redação do artigo 166 do Código Civil de 2002:

Artigo 166. É nulo o negócio jurídico quando:

I - celebrado por pessoa absolutamente incapaz;

II - for ilícito, impossível ou indeterminável o seu objeto;

III - o motivo determinante, comum a ambas as partes, for ilícito;

IV - não revestir a forma prescrita em lei;

$\mathrm{V}$ - for preterida alguma solenidade que a lei considere essencial para a sua validade;

VI - tiver por objetivo fraudar lei imperativa;

VII - a lei taxativamente o declarar nulo, ou proibir-lhe a prática, sem cominar sanção.

Bem como, o artigo 171 do mesmo código:

Artigo 171. Além dos casos expressamente declarados na lei, é anulável o negócio jurídico:

I - por incapacidade relativa do agente;

II - por vício resultante de erro, dolo, coação, estado de perigo, lesão ou fraude contra credores. 
É pacífico entre os doutrinadores que o elemento vontade se relacione intimamente com o plano da validade, significando que as condições de manifestação desse elemento devem ser livres de qualquer defeito como erro, dolo, coação, lesão, estado de perigo e outros (GAGLIANO, 2006).

Apesar das exigências apontadas nos dispositivos legais citados, há que se falar, segundo Carlos Roberto Gonçalves (2016b), na possibilidade da realização de negócios jurídicos por incapazes, principalmente no que se refere à aquisição de produtos no mercado de consumo para uso particular. Doutrinariamente, essa situação tem sido colocada como conduta social típica que independe de capacidade negocial ou vontade real ou tácita.

Para exemplificar, imagine uma criança de 8 anos de idade que compra um doce ou sorvete. Apesar de ser incapaz, isto é, não atender à necessidade de vontade qualificada exigida nos contratos de compra e venda, sua prática de compra não é considerada nula porque é dotada de ampla aceitação social (GONÇALVES, 2016b).

Sobre a temática, no ordenamento português, mais especificamente no artigo 764 do Código Civil, se um incapaz atua quando a lei exige capacidade, o pedido de anulação do negócio apenas será procedente se constatado que houve efetivo prejuízo no cumprimento efetuado (GONÇALVES, 2011).

Com isso se percebe que, embora haja todo um aparato normativo e doutrinário dos pressupostos suscitados para formação do negócio jurídico, a letra da lei não é fria, levando em consideração os costumes socialmente aceitos e se dobrando para as singularidades percebidas caso a caso, de modo a adequar o direito à sociedade e não o contrário.

\section{A vontade}

No que concerne ao elemento vontade, a doutrina se divide. Os mais clássicos afirmam que a vontade é elementar no plano de existência, constituindo-se como pressuposto essencial (PEREIRA, 2010). Novos doutrinadores, no entanto, entendem que a vontade só importa no plano da validade, porque se presentes os agentes, o objeto e a forma, o negócio jurídico já existe, independentemente da vontade (AZEVEDO, 2002).

A doutrina clássica elenca a vontade como fundamento da obrigatoriedade dos negócios face sua essencialidade, bem como, pelo fato de que qualquer homem razoável não consentiria um compromisso prejudicial para si (RANOUIL, 1980).

Segundo o Dicionário Oxford de Filosofia (1997, p. 407), "ter vontade consiste em poder desejar um resultado e ter o objetivo de realizá-lo [...]". Ainda, conceitua volição como "ato mental de querer ou tentar, cuja presença é por vezes concebida como algo que estabelece a diferença entre as ações intencionais ou voluntárias e o simples comportamento".

A vontade, portanto, existe como fenômeno psíquico, e é certo que precisa vir ao mundo de alguma forma. Quando o mecanismo de expressão da vontade corresponde exatamente à vontade em si, ao desejo, à intenção pretendida pela pessoa, não se vislumbram problemas de monta. Mas e se o que foi dito, gesticulado, escrito, demonstrado, não foi o querido? A resposta a esse questionamento movimentou grandes juristas e deu margem a significativas controvérsias (CAPELOTTI, 2010, p. 294). 
Segundo Carlos Roberto Gonçalves (2016a), a vontade quando manifesta carece invariavelmente de interpretação. Pode-se citar o contrato cuja premissa depende de ato volitivo e, portanto, de análise interpretativa. Fato é que a vontade exata das partes nem sempre é traduzida no contrato, ocorrendo por culpa, por exemplo, de má redação, verificando-se ambiguidade, obscuridade ou falta de precisão. Por essa razão, deve-se buscar uma interpretação que revele a realidade do negócio jurídico para que sua devida execução esteja de acordo com a intenção das partes.

Pode-se apontar dois tipos de interpretação: a interpretação declaratória e a interpretação construtiva ou integrativa. A primeira se observa quando o único propósito é a descoberta da intenção comum das partes quando da celebração do contrato. A segunda se percebe quando há lacunas no contrato, e o objetivo é aproveitá-lo suprindo tais omissões. Isso acontece por meio de normas supletivas que as complementam, cuja tentativa é buscar a real vontade das partes, que não raro está nas entrelinhas. A interpretação, portanto, serve-se da lei, analogia, costumes, princípios gerais de direito ou equidade para criar a norma inter partes que completará o contrato (GONÇALVES, 2016a).

De acordo com Antônio Junqueira de Azevedo (2000), o ato de vontade no negócio jurídico não é qualquer ato, precisa mais que uma atitude manifesta do agente, precisa do querer interno que revela externamente a vontade constitutiva de direito. É uma vontade qualificada. Para José de Abreu Filho (1997, p. 339), "não se pode conceber a existência de um negócio jurídico [...] se falta o elemento volitivo. Sem a manifestação da vontade o negócio não pode formar-se, evidentemente".

Por se preocupar com as implicações no mundo jurídico é que a disciplina da vontade querida versus a manifestada ainda suscita controvérsias. O que se verifica atualmente é a mitigação do pacta sunt servanda face tais preocupações com o conteúdo da relação negocial (CAPELOTTI, 2010).

Dessa forma, em caso de desconformidade entre a vontade querida e a declarada pelo agente, Augusto Passamani Bufulin (2012) escreve que há algumas teorias dispostas a resolver o conflito acerca do que se prevalece, oferecendo-se soluções com consequências diversas. Verifica-se: i) Teoria da Vontade Real; ii) Teoria da culpa in contrahendo; iii) Teoria da Responsabilidade; iv) Teoria da Declaração; e v) Teoria da Confiança.

Como não se pretende, contudo, esgotar o tema, para este trabalho serão objeto de análise apenas duas dessas teorias, por serem as candidatas mais notórias e debatidas, quais sejam: a Teoria da Vontade Real e a Teoria da Declaração.

\subsection{Conflito entre a Teoria da Vontade Real e a Teoria da Declaração}

Negociar implica um fenômeno volitivo pelo qual as pessoas, condicionadas por suas necessidades, convencionam. Nesse sentido, o Direito Alemão inaugurou suas teorias, a Willenstheorie (Teoria da Vontade), e a Erklärungstheorie (Teoria da Declaração). A relevância surge quando uma parte, ao se sentir prejudicada, aponta a não coincidência do que está expresso com o que queria (FIÚZA, 2003).

O Código Civil brasileiro tem em seu artigo 112 a seguinte redação: "Nas declarações de vontade se atenderá mais à intenção nelas consubstanciada do que ao sentido literal da 
linguagem". A partir dessa leitura parece claro o que o ordenamento jurídico privilegia atualmente. Porém, convém ir um pouco mais a fundo e verificar o que há por trás da letra da lei por meio de um estudo comparativo da Teoria da Vontade Real e a Teoria da Declaração, considerando que, na verdade, a falta de consenso quanto às suas aplicações ainda prevalece.

O teórico Savigny (apud BUFULIN, 2012) sistematizou a ideia de que o querer individual é elementar para criação de efeitos jurídicos do negócio. A vontade toma o lugar mais fulcral do polo essencial, sendo essa a Teoria da Vontade proposta por Savigny bem aceita no $\mathrm{BGB}$, pela doutrina alemã e, para além, podendo citar de forma especial a doutrina francesa.

De acordo com o teórico, são três os momentos da Willenserklärung, isto é, da declaração da vontade, sendo o primeiro a vontade em si, o segundo a sua declaração, e terceiro a identidade entre as duas. Para Savigny, esses momentos são dependentes e indissociáveis. Logo, por ser a vontade uma intimidade do agente, sua forma de ser transmitida para o mundo externo se dá pela declaração, de modo que esta é apenas um canal para a vontade (BUFULIN, 2012).

Assim, "a Teoria da Vontade entende que se não houver concordância entre a vontade e a declaração, o negócio jurídico deve ser afastado do mundo jurídico, por the faltar um elemento essencial: a presença da vontade efetiva do agente" (BUFULIN, 2012, p. 22).

Semelhantemente expõe Fernando Campos Scaff (1996), ao escrever que a Teoria da Vontade, para a matéria contratual, é peça chave, visto que os efeitos esperados devem estar conciliados com as perfeitas faculdades mentais dos contratantes, devendo o ordenamento jurídico reagir às perturbações que possam ter emergido durante a formação da vontade das partes, admitindo, se preciso, a resolução de toda a operação contratual por falta de pressuposto volitivo, que é a própria razão do negócio.

Contudo, essa visão foi alvo de duras críticas. Realmente é possível que ocorra a má-declaração da vontade, de modo a atuar em oposição às legítimas expectativas do destinatário ou não expondo o que de fato o declarante pretendia. Bem como, o destinatário não estaria isento de receber inadequadamente o que foi manifestado (SCAFF, 1996).

Assim, a Teoria da Declaração vem como uma reação aos excessos da Teoria da Vontade Real, a fim de se obter segurança jurídica com a proteção dos vínculos criados. Nesse pensamento, declarações de vontade que se revogam sem embaraço levariam as relações jurídicas privadas a uma insegurança na qual não poderiam se habituar, sem falar no óbvio, que é a impossibilidade de se acessar a vontade subjetiva, restando de concreto, para o direito, a declaração realizada (BELEZA DOS SANTOS, 1999).

A Teoria da Declaração traz uma interpretação jurídica aos elementos objetivos e socialmente reconhecíveis, de modo que o destinatário apreende a expressão concreta da linguagem, reagindo razoavelmente à vontade declarada e fazendo prevalecer o que foi efetivamente externado (SCAFF, 1996).

Por dar importância à expressão, essa teoria, também chamada de objetiva, teve apoiadores no direito italiano, como Emilio Betti, bem como, no direito alemão, como Röver, Kohler e Schlossmann. De modo diferente do que lecionava Savigny, essa teoria não separa a formação e a exteriorização da vontade. $O$ que poderia causar divergência era um engano entre uma forma, aparente e aberta, que se expressou a vontade, e outra forma, reservada e oculta, que se expressou a vontade (BUFULIN, 2012). 
Em obra pioneira no Brasil, o doutrinador Nelson Nery Jr. (1983) ensina que, se houver por parte do declarante reserva mental desconhecida do declaratário, o conflito será resolvido pela Teoria da Declaração. Se for o caso da existência de reserva mental conhecida do declaratário, o conflito será resolvido pela Teoria da Vontade.

Diante do conflito das teorias, Humberto Theodoro Jr. (2001, p. 119) chama a atenção para os vícios de consentimento nas declarações de vontade, e explica que:

\begin{abstract}
Levada ao extremo, todo ato afetado por vício de consentimento seria inválido diante da ausência de vontade de que se ressente, seja por erro, dolo ou coação, ou por qualquer outro evento que impeça sua livre e consciente manifestação. Essa proteção ampla e irrestrita à vontade real não é, todavia, acolhida pela ordem jurídica, porque entraria em choque com o interesse geral, afetando a segurança das relações negociais. Se de um lado existe o interesse do declaraste, que praticou o negócio jurídico e que deseja preservar a pureza de sua vontade; de outro, há o interesse do meio social, onde o negócio jurídico estabelece uma expectativa de que a declaração de vontade produzirá os efeitos programados, não podendo, razoavelmente, aceitar que, por motivos íntimos do declaraste, se estabeleça o perigo da sua fuga da obrigação assumida.
\end{abstract}

Frente toda discussão que permeia entre as teorias da vontade e da declaração, o Código Civil brasileiro se posicionou em defesa da vontade real, ao redigir em seu ordenamento os vícios de consentimento e tornar possível a anulação dos negócios em que os verificarem, quais sejam: coação, dolo, lesão, estado de perigo etc. (THEODORO JR., 2001).

No entanto, Azevedo (apud CAPELOTTI, 2010) defende que todo esse debate em torno de qual teoria prevalece é estéril, uma vez que a vontade é o pressuposto da existência e não o elemento dela, se consubstanciando, assim, na declaração. Isto é, a vontade e a declaração devem atuar em conjunto para que - com os outros elementos - o negócio exista. O ponto está, na verdade, no plano da validade, carecendo a observância das hipóteses de nulidade e anulabilidade e até de validação por decurso do prazo.

Embora haja essa discussão acerca de qual teoria se prevalece, na realização dos negócios a declaração e a vontade são interdependentes. É preciso a presença das duas. Segundo Carlos Roberto Gonçalves (2016a), parte-se da declaração escrita para se chegar à vontade dos contratantes, de modo que o texto redigido, por exemplo, no contrato, induz a intenção das partes, em regra. Então, ressalte-se que a questão reside na fidelidade ou não da vontade manifestada quando celebrada a avença, já que a mesma pode ser questionada em determinadas circunstâncias.

"Não se pode aplicar separadamente a Teoria da Vontade e a da Declaração, mas conjuntamente, visto que constituem faces de um mesmo fenômeno." Segundo o autor, caso se busque a vontade real, o interesse não reside nos motivos intrínsecos dos declarantes, mas sim na boa-fé dos mesmos na realização do negócio a fim de atribuir a mais adequada interpretação (GONÇALVES, 2016a, p. 308).

César Fiúza (2003) explica que interpretar é aplicar princípios ao caso concreto, considerando que o Código Civil brasileiro é carente de normas de hermenêutica contratual, trazendo apenas artigos como o 112 e o 114, em que o primeiro expressa a prioridade da intenção sobre o sentido literal do texto, e o segundo requer interpretação restritiva aos 
contratos benéficos, como doação e fiança. Cita o autor, ainda, para apontar dispositivos principiológicos, os artigos 421, 422 e 423. Interpretar cabe à doutrina e à jurisprudência, não ao legislador.

"Importante para a correta análise do problema é perceber que não se pode aprioristicamente apontar uma teoria que se aplique, de forma única, aos inúmeros problemas surgidos com a divergência entre a vontade real e a vontade declarada" (BUFULIN, 2012, p. 30).

A hermenêutica tem lugar quando as partes se desentendem, sendo papel do hermeneuta apaziguar a celeuma a partir da minuciosa análise do contrato, suas razões, elementos sociais e econômicos, circunstâncias, a finalidade e demais aspectos subjetivos e objetivos. Cabe ao hermeneuta ver por meio da declaração para alcançar o real, observando a presença ou não de má-fé. São os detalhes do caso concreto que permitirão concluir (FIÚZA, 2003).

A lei não cobre todos os aspectos da vida em suas minúcias, e no que cobre, deve estar a todo momento reexaminando seus padrões a fim de se adequar às evoluções constantes do cenário social. Por isso, discutir as teorias, embora historicamente tão já repassadas, tem seu mérito, visto que se predispõem ao nobre objetivo de promover paz onde se aplicam, ainda que sua aceitação varie ao longo do tempo e lugar.

\section{CONSIDERAÇõES FINAIS}

O negócio jurídico é mais que uma disciplina técnica dentro do Código Civil brasileiro apreciada por juristas, é saber prático habitualmente presente na vida de todos, desde os mais leigos particulares que convencionam as coisas mais simplórias em suas rotinas, sem nem mesmo se darem conta de que o que fazem é objeto do vasto estudo civilista, até os mais doutos, que discutem variadas teses acerca da matéria. Isso demonstra o alcance e a tangibilidade dos resultados teóricos dentro de uma ciência social.

Após observado que o negócio jurídico possui sua estrutura dividida em planos - o da existência, o da validade e o da eficácia -, conhecida na doutrina brasileira por Escada Ponteana, foi possível compreender os pressupostos de cada um deles para, apenas assim, se identificar com sabedoria onde a vontade se integra como elemento cardeal.

A vontade é o que domina toda a discussão, tendo sua importância questionada já na divisão dos planos, em que alguns doutrinadores entendem estar no plano da existência e outros, na validade. Sendo a vontade suscitada como o mais relevante preceito do negócio jurídico, há hoje a mitigação do brocardo pacta sunt servanda, considerando que os calorosos debates em volta do ato volitivo dão razão ao não engessamento das consequências derivadas desse ato.

Isso significa que há sim prestígio nas hipóteses ensejadoras de nulidade, anulabilidade e até validação do ato, em razão de defeitos descobertos no momento de manifestação do querer. Isso revela a tendência do ordenamento jurídico brasileiro em favorecer a Teoria da Vontade Real em detrimento da Teoria da Declaração, uma vez que a possibilidade de se revisitar e priorizar a intenção do declarante se alinha com o teor da primeira teoria.

Porém, há que se lembrar dos defensores de que as duas teorias são indissociáveis e que não competem entre si, mas sim se completam. Diante de uma sociedade tão plural, 
com problemas igualmente plurais, não convém apontar um único posicionamento como solucionador de tudo.

Conclui-se, portanto, que a eleição simplesmente de uma teoria não basta, apesar da inclinação vigente à Teoria da Vontade Real. A ordem está no interpretar as particularidades de cada caso, conduta essa amplamente regida por princípios garantidores da adequada verificação da boa-fé e outros elementos que levarão ao mais próximo da justa resolução.

\section{REFERÊNCIAS}

ABREU FILHO, José de. O Negócio Jurídico e sua Teoria Geral, 4. ed. São Paulo: Saraiva, 1997.

AZEVEDO, Antônio Junqueira. Negócio Jurídico, 4. ed. São Paulo: Saraiva, 2002.

AZEVEDO, Antônio Junqueira. Negócio Jurídico: Existência, Validade e Eficácia, 31. ed. São Paulo: Saraiva, 2000.

BELEZA DOS SANTOS, José. A Simulação em Direito Civil. São Paulo: Lejus, 1999.

BLACKBURN, Simon. Dicionário Oxford de Filosofia. Rio de Janeiro: Zahar, 1997.

BRASIL. Lei n⿳0. 10.406, de 10 de janeiro de 2002. Institui o Código Civil. Brasília, DF, Disponível em: http:/www.planalto.gov.br/ccivil_03/leis/2002/110406.htm. Acesso em: 31 jul. 2019.

\section{BUFUlin, Augusto Passamani. Os Requisitos do Erro de Acordo com a Teoria Adotada} pelo Código Civil Brasileiro de 2002, 2012, 231s. Tese (Doutorado) - Curso de Direito, Direito Civil, Pontifícia Universidade Católica de São Paulo, São Paulo, 2012. Disponível em: https://tede2.pucsp.br/bitstream/handle/6078/1/Augusto\%20Passamani\%20Bufulin. pdf. Acesso em: 15 mai. 2019.

CAPELOTTI, João Paulo. O contrato como expressão da autonomia da vontade em face dos métodos contratação em massa. Revista Cesumar: Ciências Humanas e Sociais Aplicadas, Maringá, v. 15, n. 2, p. 291-310, Não é um mês válido! 2010. Disponível em: http:// periodicos.unicesumar.edu.br/index.php/revcesumar/article/view/1089/1115. Acesso em: 12 mai. 2019.

FIÚZA, César. Direito civil: curso completo, 6. ed. rev., atual, e ampl. de acordo com o Código Civil de 2002. Belo Horizonte: Del Rey, 2003.

GAGliAnO, Pablo. Novo Curso de Direito Civil, 8. ed. São Paulo: Saraiva, 2006.

GONÇALVES, Carlos Roberto. Direito Civil Esquematizado 1: Parte Geral Obrigações e Contratos, 6. ed. São Paulo: Saraiva, 2016a, 1.001 p. 
GONÇALVES, Carlos Roberto. Direito Civil Esquematizado 2: Contratos em Espécie e Direito das Coisas, 4. ed. São Paulo: Saraiva, 2016b. 892 p.

GONÇALVES, Carlos Roberto. Direito Civil Brasileiro, Volume 2: Teoria Geral das Obrigações, 8. ed. São Paulo: Saraiva, 2011, 433 p.

MELLO, Marcos Bernardes de. Teoria do Fato Jurídico, 5. ed. São Paulo: Saraiva, 1993.

NERY JR, Nelson. Vícios do Ato jurídico e Reserva Mental. São Paulo: RT, 1983.

PEREIRA, Caio Mário da Silva. Instituições de Direito Civil, 23. ed. Rio de Janeiro: Forense, 2010.

PONTES DE MIRANDA, Francisco. Tratado de Direito Privado, 4. ed. São Paulo: RT, 1974. T. III.

PONTES DE MIRANDA, Francisco. Tratado de Direito Privado, 2. ed. Rio de Janeiro: Borsoi, 1954. T. IV.

RANOUIL, Véronique. Autonomie de la Volonté, 1. ed. Paris: Presses Universitaires de France, 1980.

RODRIGUES, Silvio. Direito Civil. São Paulo: Saraiva, 2002.

SCAFF, Fernando Campos. As novas figuras contratuais e a autonomia da vontade. Revista da Faculdade de Direito: Universidade de São Paulo, São Paulo, v. 91, p. 141-159, $1^{\circ}$. jan. 1996. Disponível em: http://www.revistas.usp.br/rfdusp/article/view/67332. Acesso em: 12 mai. 2019.

TARTUCE, Flávio. Manual de direito civil, 2. ed. São Paulo: Método, 2012.

THEODORO JUNIOR, Humberto. Dos Efeitos do Negócio Jurídico no Novo Código Civil. Revista da Faculdade de Direito da Universidade Federal de Minas Gerais, Belo Horizonte, v. 40, p. 91-123, 2001. Disponível em: https://www.direito.ufmg.br/revista/index.php/revista/article/view/1215/1148. Acesso em: 28 mar. 2019.

VELOSO, Zeno. Fato Jurídico, Ato Jurídico, Negócio Jurídico. Revista de Informação Legislativa, Brasília, v. 32, n. 125, p. 87-95, jan. 1995. Disponível em: http://www2.senado.leg.br/bdsf/handle/id/176311. Acesso em: 28 mar. 2019.

\section{DADOS DA AUTORA}

\section{Melissa Pinheiro Almeida}

Advogada; Pós-graduanda em Gestão de Negócios pela Universidade de São Paulo (campus Piracicaba); Bacharela em Direito pelo Centro Universitário Adventista de São Paulo (campus Engenheiro Coelho).melissapinheiro@hotmail.com 